УДК 330.342

ББК 65.011 .3

DOI 10.17150/2308-2588.2017.18(2).387-406

Я. С. Ядгаров

Финансовый университет при Правительстве РФ, г. Москва, Российккая Федерация

В. А. Сидоров

Кубанский государственный университет, г. Краснодар, Российская Федерация

\title{
V МЕЖДУНАРОДНАЯ НАУЧНО-ПРАКТИЧЕСКАЯ КОНФЕРЕНЦИЯ ІФЕНОМЕН РЫНОЧНОГО ХОЗЯЙСТВА: ОТ ИСТОКОВ ДО НАШИХ ДНЕЙ॥
}

Аннотация. Обзорная презентация докладов (выступлений) участников V Международной научно-практической конференции, посвященной памяти крупного организатора отечественной экономической науки доктора экономических наук, первого профессора политической экономии на Юге России (Кубани) А. Ф. Сидорова.

Ключевые слова. Международный научно-практический форум, эволюционные аспекты феномена рыночного хозяйства, государственное регулирование экономики, социально ориентированная рыночная экономика.

Ya. S. Yadgarov

Financial University under the Government of the Russian Federation, Moscow, Russian Federation

V. A. Sidorov

Kuban State University, Krasnodar, Russian Federation

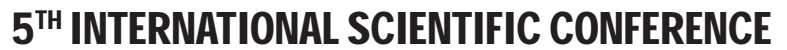
IIPHENOMENON OF MARKET EBONOMY: FROM THE ORIGINS UNTIL NOWII

Abstract. The article presents reports of the $5^{\text {th }}$ International Scientific and Practical Conference dedicated to 
A. F. Sidorov, a famous economist, Doctor of Economic Sciences and the first Political Economy Professor of the South of Russia.

Keywords. International Scientific and Practical forum, developmental aspects of market economy phenomenon, governmental management of the economy, socially oriented market economy.

В постсоветский период представители российского научного экономического сообщества все более отчетливо осознают настоятельную необходимость комплексного анализа, систематизации и обобщения результатов исследования векторов и особенностей различных моделей рыночной системы хозяйствования в контексте эволюции альтернативных методологических и теоретических идей, воззрений и концепций по данной проблематике. При этом в числе прочего они, как очевидно из их изысканий, приходят к пониманию того, что «...ныне для отечественных ученых-экономистов и практиков в области хозяйственной жизни наиболее предпочтительными могли бы быть термины "рыночная экономика" или "рыночные экономические отношения" » ${ }^{1}$.

Данные обстоятельства явились предпосылками, обусловившими необходимость ежегодного проведения в Сочи (начиная с 2013 г.) научно-практической конференции историко-экономической направленности на тему: «Феномен рыночного хозяйства: от истоков до наших дней», посвящаемой памяти крупного организатора отечественной экономической науки на Юге России (в Кубани) - доктора экономических наук, первого профессора-политэконома Александра Федоровича Сидорова. Следует, правда, заметить, что в последние два года (2016 и 2017 гг.) их проведение претерпело определенную организационную кор-

${ }^{1}$ Ядгаров Я. С. История экономических учений: учеб. 4-е изд., прераб. и доп. М.: ИНФРА-М, 2007. С. 15.

2017 , vol. 18 , no. 2 , pp. $387-406$ 
ректировку, в соответствии с которой пленарные заседания проходили в течение первого и второго дня в Сочи; мероприятия же заключительного третьего дня проходили на выездном заседании (в формате круглого стола) в Абхазском государственном университете. В частности, на V форуме, состоявшемся в текущем 2017 г., в качестве центральной во главу угла вновь была поставлена проблематика осмысления эволюционных аспектов феномена рыночного хозяйства. Активное участие в нем приняли ученые-экономисты ряда российских и постсоветских зарубежных университетов и научно-исследовательских структур, а его мероприятия проходили в период 30 и 31 марта в Сочи и 1 апреля - в Сухуме.

В Оргкомитет конференции вошли ученые-экономисты Кубанского госуниверситета, Финансового университета при Правительстве Российской Федерации, Российского экономического университета им. Г. В. Плеханова, НИИ экономики Южного федерального округа, Российского государственного аграрного университета - МСХА им. К. А. Тимирязева, Ивановского государственного университета. Зарубежными членами Оргкомитета явились представители Международного казахско-турецкого университета им. Х. А. Ясави, Белорусского государственного аграрного технического университета, Ереванского, Абхазского, Днепропетровского им. Альфреда Нобеля госуниверситетов, Луганского национального аграрного университета, Каршинского инженерно-экономического института (Узбекистан), Приднестровского государственного университета им. Т. Г. Шевченко. Соответственно в работе конференции участие приняли ученые таких постсоветских государств и регионов как Россия, Абхазия, Армения, Грузия, Украина, Казахстан, Узбекистан.

На первом пленарном заседании конференции со вступительным словом выступил Сопредседатель орг2017. T. 18, № 2. C. 387-406 
комитета член-корреспондент РАН, доктор экономических наук, профессор, Научный руководитель Финансового университета при Правительстве Российской Федерации Д. Е. Сорокин. Он обратил внимание аудитории на особенности развития институциональных оснований феномена рыночного хозяйства в контексте все еще встречающихся попыток создать такие концепции, в которых отрицается закономерный характер становления и эволюции рыночной организации экономики. Но такого рода попытки, подчеркнул оратор, лежат за пределами науки, и поэтому вопрос о соотношении роли государства и рыночных механизмов остается ключевым для нынешних и предстоящих научных дискуссий. По его мнению, развитие рыночных институтов является абсолютно необходимым условием перехода к устойчивому социально-экономическому развитию, однако для обеспечения этого перехода требуется, чтобы теоретические концепции экономического роста не просто превратились в прикладные инструменты экономической политики, но и корреспондировались с политико-экономическими реалиями страны, как внешнего, так и внутреннего характера. Поэтому применительно к реалиям сегодняшней России в части задачи перехода ее экономики на новый технологический уклад, убежден ученый, единственным субъектом, способным осуществить этот прорыв, остается государственная инвестиционная активность.

В то же время, продолжил Д. Е. Сорокин, рассматриваемый факт (базирующийся на генетической памяти о всесильном государстве, сформированный в далекой исторической ретроспективе и дополняемый неизбежным стремлением государства к патернализму) порождает риск превращения государственной инвестиционной активности в единственный безальтернативный источник экономического развития. Теория «предупреждает», что государственные инвести- 
ции, в силу объективно присущих большим системам ограничениям, способны обеспечить лишь точечные прорывы, но никак не комплексное социально-экономическое развитие страны. Отсюда главной задачей экономической науки становится, во-первых, выработка концепции технологического перевооружения, предполагающей активную инвестиционную политику государства. И, во-вторых, одновременно с этим обоснование концепции развития инвестиционной активности предпринимательского сектора, постепенно берущего на себя роль главного драйвера экономического развития.

В выступлении профессора Я. С. Ядгарова (Финуниверситет) был подведен итог его многолетних историко-экономических исследований, касающихся непосредственно феномена рыночного хозяйства как неотъемлемой части социально-политической системы. Общий фон его доклада может быть детерминирован следующим образом.

1. Идеи регулирования экономики, впервые обозначив себя во времена натурально-хозяйственной идеологии (в воззрениях древних правителей, мыслителей и средневековых схоластов) и перманентно эволюционируя в соответствующие периоды рыночной системы хозяйствования (в изысканиях адептов политической экономии меркантилизма, классической политэкономии и их противников, «ортодоксального» и «зрелого» неоклассицизма и институционализма), проявляют себя доминирующей составляющей экономического анализа.

2. В периоды Древнего мира и Средневековья и господства тогда принципов натурального хозяйства содержательная составляющая идей регулирования экономики сводилась (с позиций морали, этики и нравственности) к обоснованию политики сдерживания тенденций расширения масштабов товарно-денежных отношений, их жесткой перманентной регламента2017. T. 18, № 2. C. 387-406 
ции, отторжения лежащих в основании рыночной системы хозяйствования принципов доминирования частной собственности, свободного ценообразования.

3. Зарождение рыночного хозяйства и формирование экономической науки обусловили возникновение альтернативных идей регулирования рыночной экономики (соответственно в периоды политической экономии меркантилизма, классической школы и ее противников), ставших предтечей современных теорий государственного регулирования экономики и политики социального контроля общества над экономикой; при этом в контексте феномена рыночного хозяйства и идей его регулирования исключение составляет лишь период апогея классической политической экономии и раннего неоклассицизма (то есть XIX и отчасти начало XX века), на который приходится творчество адептов двух всемирно известных либеральных триумвиратов ученых-экономистов, как-то: Рикардо - Сэй - Мальтус и Маршалл - Кларк Парето.

4. В период меркантилизма, явившего собой переход от натурального хозяйства к рыночной системе хозяйствования, вновь возникшие идеи регулирования рыночной экономики привлекли к себе широкое внимание и теоретиков и экономистов-практиков, способствуя тем самым становлению многообразных институтов всеохватных рыночных экономических отношений и зарождению политической экономии как науки о регулируемой экономике национальных государств.

5. «Первые» и «последние» представители классической политэкономии во многом небезосновательно критиковали протекционистскую экономическую политику меркантилистов, выступая за полное отмежевание государства от исполнения им определенных координирующих и регулирующих функций; однако они, не обойдясь в своих суждениях без использования рекомендаций, выходящих за рамки действия «объек- 
тивных экономических законов», допускали идеи регулирования рыночной экономики.

6. Противники классической политической экономии, отвергая доктрину laissez faire, положили начало нелиберальной политической экономии экономического романтизма и утопического социализма, обратившись к моделированию регулируемой хозяйственной жизни будущего, которая должна опираться на менталитет, нравы, коллективную психоло ᄀгию, предопределяя грядущую смену нынешней им экономической модели социально ориентированной хозяйственной системой.

7. Главным образом аналитические нововведения институционалистов, кейнсианцев и неолибералов способствовали кардинальному переосмыслению сущности феномена рыночного хозяйства и пониманию того, что этот тип хозяйства не является автоматически ни саморегулирующейся системой, ни некой не подлежащей сомнению данностью.

8. Ключевая задача современного научного экономического сообщества состоит в обосновании таких социально ориентированных теоретических и реформаторских программ регулирования рыночной экономики, которые бы обеспечивали бескризисное (нециклическое), эффективное и поступательное социально-экономическое развитие.

Профессор Всероссийской академии внешней торговли при Минэкономразвития РФ Ильинова В. В. посвятила свое выступление эволюционным аспектам теории риска в рыночной экономике. Выделяя и сопоставляя особенности в экономической науке классической и неоклассической версий теории предпринимательских рисков, она считает, что объединяющим для них началом служит плата за риск, выступающая в различных формах. В результате анализа подходов классиков и неоклассиков профессор приходит к заключению о связи прибыли и риска, акцентируя при этом внима2017. T. 18, № 2. C. 387-406 
ние на фундаментальном подходе к категории риска (Ф. Найт), кейнсианской теории предпринимательского риска и современных версиях ее интерпретации Г. Марковицем, У. Шарпом, Г. Модильяни, Н. Блейком, М. Шоулзом и другими. Последнее десятилетие показало, что наука о риске становится одной из ведущих в XXI веке из-за устойчивого роста многообразия и масштабов проявления рисков и связанных с ними проблем. В связи с этим встает проблема возможности управления риском и привязке ее к созданию международных стандартов по регулированию рисков.

Надо сказать, отметила она далее, что опыт исследований в этом направлении накоплен достаточный. Начиная с 1974 г., когда был создан Базельский комитет по банковскому надзору, один за другим стали появляться институты контроля над рисками: Институт управления рисками (1984 г., Великобритания), Международная ассоциация специалистов по управлению рисками (1999 г., США), рабочая группа для разработки руководства определения, применения и практики риск-менеджмента (2005 г., ISO). Результатом их работы стал интегрированный подход к учету и управлению всеми рисками. В рамках данного подхода произошло появление системы, способной анализировать различные факторы риска в единой интегрированной и согласованной среде. Данное обстоятельство позволяет говорить о появлении в арсенале компаний системы интеллектуального управления рисками - концепции, ориентированной на поддержание разумного баланса между риском и доходностью. Проще говоря, организации создают стоимость, идя на риск, и теряют ее, так как оказываются неспособными управлять риском. Эффективная система управления рисками нацелена одновременно на создание и сохранение стоимости.

В структурном отношении методология интеллектуального управления рисками включает, по мнению докладчика, следующие основные разделы: 
- свод правил управления рисками, которые распространяются на всю компанию и связанные активы;

- стратегии для всего спектра рисков;

- процессы, направленные на повышение надежности бизнеса и снижение степени его уязвимости;

- подходы, учитывающие сценарии рисков и их взаимодействие;

- правила, ставшие неотъемлемой частью корпоративной культуры;

- риск-философию, которая ориентирована не только на негативные последствия, связанные с риском, но и на возможности, которые появляются при том или ином событии.

Внедрение интеллектуального управления рисками, подытожила докладчик, позволяет организации разрабатывать эффективную стратегию развития в рыночном хозяйстве, наиболее полно учитывая те изменения, которые происходят во внешней и внутренней средах организации.

Профессор В. А. Сидоров (Кубанский госуниверситет) посвятил свой доклад вопросам эволюции институциональных аспектов междисциплинарного подхода к оценке природы экономических явлений и процессов. Автор, сосредоточившись на поиске основания экономической теории, считает, что он имеет системно организованный научный базис, ориентированный на самоорганизующиеся системы. Фрактальная природа экономики означает, что ее разноуровневые структуры - глобальный, национальный, локальный, местный и корпоративный - имеют много общего. Каждый уровень, полагает он, содержит экономические системы, находящиеся на разных этапах своего развития и функционирующие в разном экономическом времени, что генерирует определенную неоднородность каждого уровня. Например, в рамках классической политической экономии сформировался тезис о богатстве наций с присущими ему критериальными 2017. T. 18, № 2. C. 387-406 
оценками: результат материального производства, величина общественного продукта, его структура и динамика. Идеи маржинализма дали миру понимание важности поведенческой онтологии: обмен, процесс непосредственной деятельности, поведение экономических агентов. Они, в свою очередь, были развиты институционализмом в части того, что характер поведения зависит от сложившихся правил, норм, привычек, традиций. То есть одной и той же картине экономической реальности соответствует собственная эмпирическая база и методы изучения: рыночные цены могут существовать как в форме трудовых затрат, спроса и предложения, договора сделки, так и общественной нормы обмена (в экономической науке соответственно - продуктовая, поведенческая и институциональная онтологии).

Приведенные сравнения, по мнению докладчика, доказывают неоднородность экономического времени, из чего, в первом приближении, вытекают принципы фрактальности: неодинаковость уровней экономики; неоднородность структуры каждого из уровней; наличие однотипного ядра внутри каждой структуры, придающего различным их уровням относительно сходную структуру; сохранение неоднородности структур на протяжении эволюции экономики. Отсюда вытекает, что категория фрактала не только может быть использована в характеристиках континуального органического целого, но и выступить в качестве новой идеи описания типологии объектов, философского основания экономического знания. То есть, появляется возможность по-новому взглянуть на проблему поиска основания экономического знания при описании совокупности экономических явлений и процессов и отдельных явлений и процессов, реализуемых в системном подходе при анализе суммативных и интегративных систем. В связи с этим важным является не столько поиск инструментов, с помощью которых исследуется 
новое качество экономической жизни, сколько преемственность экономического знания, исходящего из элементов классицизма и обогащенного содержанием агломерации знаний междисциплинарного порядка. По-видимому, заключает ученый, таково направление поиска неизвестных качеств экономических явлений и процессов современного мира.

Профессор Южного федерального университета В. Н. Овчинников, раскрывая результаты своего изыскания, направленного на раскрытие содержания понятия «рыночно-экономическое пространство», пришел к заключению, что данная дефиниции может быть охарактеризована как континуум экономических взаимодействий субъектов. Данное понятие, с его точки зрения, в содержательном плане следует дифференцировать для глобального экономического пространства (мировой рынок) и национально-государственного экономического пространства (внутренний рынок), а также для регионального экономического пространства (региональный рынок) и субрегионального экономического пространства (локальный рынок). Емкость же этих структур, полагает он, определяется мерой насыщения платежеспособного спроса, ибо сам факт наличия свободных рыночных ниш и плотность экономического пространства определяются степенью насыщения («заполнения емкости рынка»). При насыщенном рынке (рынке потребителя) удовлетворенный спрос ограничивает активность субъектов предложения (и стоящих за ними производителей), рыночноэкономическое пространство их производственно-хозяйственной активности сужается. Такой подход, по мнению ученого, позволяет методологически четко выделить уровни иерархической структуры современной рыночно-экономической системы, идентифицировать ее субъектов, соответствующих каждому уровню и определить формат экономического пространства их воспроизводственной базы. 
В своем сообщении Г. П. Журавлева - профессор РЭУ им. Г. В. Плеханова - поставила перед собой задачу обосновать объективную необходимость формирования новой теоретической модели социально-экономического развития (НМСЭР). По ее мнению, данная проблематика становится особенно важной на данном этапе эволюции экономической мысли в связи с тем, что ныне действующая в России модель социальноэкономического развития большинством научного сообщества признается неудовлетворительной во многом по причине неэффективности государственной власти. Для вновь сложившихся на постсоветском пространстве условий, на ее взгляд, характерна как модификация множества категорий, так и возникновение значительного числа категорий и понятий, требующих их теоретико-методологического осмысления. В их числе имеют место даже весьма неоднозначные словосочетания: интеллектуальный капитал; инновационный менеджмент; нематериальный капитал в форме интеллектуальной собственности; преобразование системы деловых связей в систему гибких альянсов; репутация в брэнд; талант сотрудников и другие. В условиях НМСЭР, подчеркивает она, меняется природа собственности и природа фир ᄀмы, формируется новый тип рациональности, возникает новое понимание и иная расстановка «имулщих» и «неимущих», очевидным становится формирование и развитие виртуального сектора экономики. Согласно выводу докладчика, в целом НМСЭР присущ целый ряд принципиальных отличий, что позволяет говорить об изменении отдельных макроэкономических параметров, как на внутреннем рынке, так и в международном масштабе.

Доклад профессора Р. М. Нуреева (Финуниверситет) был посвящен историко-экономическому анализу различных теоретико-методологических граней исследовательских доктрин в прошлом и настоящем в контексте воспроизводственной парадигмы. Докладчик 
представил собственную версию интеллектуального осмысления новой модели социально-экономического развития общества в тесной связи с современной парадигмой феномена рыночного хозяйства. Аргументировал сентенции о том, что вне системного подхода решить проблемы российской экономики, по-видимому, не удастся, поскольку согласование пропорций достигается тем, что их формирование подчиняется объективным требованиям условий хозяйствования. Ученый, кроме того, представил собственное видение перспектив развития инновационной системы России, предложил алгоритм процессного подхода к осмыслению реалий рыночной экономики, в которой стратегия конкурентных преимуществ строится главным образом на роли компаний с государственным участием. Особое внимание было уделено им также анализу функций рынка и государства в региональном воспроизводстве, результатов антироссийских экономических санкций в связи с издержками и выгодами конфронтации.

В качестве итоговых оратор представил два варианта прогноза ближайшего развития событий с точки зрения рядового потребителя. Это - пессимистический и оптимистичный варианты. Пессимистический прогноз увязывается с дальнейшим усилением экономических санкций и продолжением падения цен на нефть. В этом случае произойдет углубление экономической изоляции России от мирового сообщества. Любые шаги в этом направлении могут привести к последствиям, о которых многие участники экономического конфликта в краткосрочном периоде даже не догадываются. Результатом оптимистического прогноза должны явиться ослабление экономических санкций, увеличение в российском импорте доли западных товаров, диверсификация товарных потоков и партнерство со странами, предоставляющими режим наибольшего благоприятствования для России. В этом 2017. T. 18, № 2. C. 387-406 
случае усилится конкуренция импортных товаров с отечественными товарами, и российским производителям придется работать в условиях международной конкуренции. К сожалению, не все из них будут к этому готовы.

Академик Академии философии хозяйства, доцент В. В. Чапля (Кубанский госуниверситет), изучив и обобщив комплекс историко-экономических идей в области осмысления проблем опыта моделирования динамического перехода на контролируемых рынках, предложил авторское видение модели формирования теневых отношений в сфере ценообразования, налогообложения, риска. Отметил, что результаты проведенных исследований теневого бизнеса как структуры хозяйственной системы общества, особенно на этапе нынешних рыночных преобразований, убеждают в том, что эта структура находится в состоянии сложной трансформации и требует как никогда прежде пристального внимания исследователей и государственных институтов К ним.

Д.э.н., доцент М. И. Сидорова (Финуниверситет) представила авторскую версию интерпретации эволюции идей в области управленческого учета как инструмента оптимизации управленческих решений в условиях рыночного хозяйства. С ее точки зрения ныне исторически сложились и обособились следующие три самостоятельных направления учета. Это, во-первых, учет производственных затрат (вследствие возникновения крупной машинной индустрии, распространения акционерной формы собственности, развития различных форм концентрации и кооперации производства). Во-вторых, учет на базе концепции «стандарт-кост» (как мера оценки эффективности производственных процессов). И, в-третьих, учет, предполагающий оптимизацию управленческих решений на основе информации о затратах на производство в связи с тем, что усиливающаяся концентрация производства и рост 
его объемов поставили вопрос о децентрализации систем управления, так как потребности рынка требуют применения более гибкого, ситуационного подхода в менеджменте.

Профессор Гайсин Р. С. (Российский государственный аграрный университет - МСХА им. К. А. Тимирязева) представив в своем выступлении видение особенностей эволюции аграрных кризисов перепроизводства и механизмы их регулирования, подчеркнул, что в течение $X X$ века обращают на себя внимание два периода в развитии и нарастании кризисных процессов. Первый период (до 1980-х гг.) характеризуется относительным перепроизводством, а второй (начался в 1980-е гг.) - характеризуется абсолютным перепроизводством. Высказал убеждение об объективной необходимости государственного вмешательства в механизм уравновешивания спроса и предложения, выработки государственнойантикризиснойполитики, какпосредством прямых, так и косвенных мер поддержки спроса населения на продовольствие (в первую очередь поддержка спроса населения с низким уровнем доходов). По мысли ученого, в странах с развитой рыночной экономикой сложился опыт широкого использования мер, направленных на повышение спроса, на продовольствие со стороны малообеспеченных слоев населения посредством целевого расходования государственных средств. Повышение спроса на сельскохозяйственную продукцию со стороны государства, подчеркнул он далее, являет собой политику расширения инвестиций и спроса, поддержки производителей продукции, уравновешивания спроса и предложения без спада производства, поддержки цен и доходов производителей.

Продолживший дискуссию профессор Б. С. Мырзалиев (Международный казахско-турецкий университет им. Х. А. Ясави, Казахстан), затронул актуальные проблемы развития социальной инфраструктуры сельских территорий в периоды истекшего столетия и в 2017. T. 18, № 2. C. 387-406 
начале нынешнего века. Он, в частности, пришел к выводу о том, что лишь в постсоциалистический период в Казахстане удалось обеспечить радикальное реформирование экономики, что в свою очередь позволило обеспечить становление и развитие рыночных отношений в стране. Преобразование сельских населенных пунктов, имеющих ныне достаточно развитую социальную и производственную структуру в поселения со статусом агрогородков, как конкурентоспособных и самодостаточных хозяйственных комплексов, явится надежной основой продовольственной безопасности страны, роста производительности аграрного труда, более полной занятости населения, получения ими приемлемых доходов, воспроизводства и экономической активности рабочей силы в сельской местности.

Ученый сформулировал также выводы о том, что для устойчивого развития сельских территорий, во-первых, необходимо создать соответствующие правовые, экономические и организационные основы, что является прерогативой государственных органов и органов местного самоуправления. Во-вторых, целесообразно осуществить переход к новому административно-территориальному устройству при определении статуса сельских поселений с учетом уровня их урбанизированности и новых критериев деления территориальных образований на городские и сельские. В-третьих, требуется создание на кооперативных началах государственно-частного партнерства, обладающего большими возможностями обслуживания крестьянских хозяйств и товариществ в сфере производства, сбыта и переработки сельскохозяйственной продукции, которое могло бы стать экономическим ядром формирования населенного пункта нового типа - агрогорода как наиболее перспективного кластерного проекта.

Член-корреспондент НАН Г. И. Гануш (Белорусский государственный аграрный технический университет) изложил результаты своих историко-экономи- 
ческих исследований в области развития и трансформации адаптивных систем ведения сельского хозяйства Беларуси в контексте прогрессирующей динамики рыночных процессов. Обратив внимание на преобладание техногенных технологий, являющихся тормозом в развитии сельского хозяйства, оратор отметил необходимость систем адаптивного типа, способных активизировать практическое воплощение принципов «зеленой экономики», органических агротехнологий, других современных процессов, обеспечивающих рациональный рост производства продовольствия и сельскохозяйственного сырья при максимальном соблюдении требований охраны окружающей среды. В числе задач формирования условий эффективного освоения в АПК адаптивных систем хозяйствования, подчеркнул ученый, приоритетное значение имеет решение таких, как: повышение уровня профессиональной подготовки руководителей и специалистов АПК; расширение рамок экономической свободы субъектов хозяйствования; совершенствование взаимодействия аграрной науки и производства; развитие диверсификации агропроизводства и других. Докладчик предложил также алгоритм поэтапного перехода к адаптивным системам сельскохозяйственного производства с учетом природных, экономических и иных особенностей их функционирования.

Наконец, как отмечалось выше, отличительной чертой конференции явился заключительный ее этап, который проходил в формате «круглого стола» по проблемам экономического образования на базе Абхазского госуниверситета в г. Сухум. Приехавших в вуз участников конференции тепло приветствовал его ректор академик А. А. Гварамия. Модераторами этой части конференции стали профессоры кафедр теоретической экономики Е. Н. Калайдин и маркетинга и управления предприятием КубГУ Г. М. Мишулин, а также доцент кафедры экономической теории и 2017. T. 18 , № 2. C. 387-406 
управления Волжского гуманитарного института (филиала) Волгоградского государственного университета Ю. Н. Чернявская. Их выступления по проблематике воспроизводства академического знания послужили импульсом последующего обсуждения и дискуссии.

С обобщающими сентенциями на данном «круглом столе» выступили: А. А. Гварамия, Р. М. Нуреев, Я. С. Ядгаров, В. А. Сидоров, 3. И. Шалашаа, Б. С. Мырзалиев, Н. У. Узаков, Г. Л. Саргсян, В. Н. Овчинников, А. Н. Багба, Е. Н. Калайдин, Л. Г., В. О. Мосейко, В. Г. Ткаченко, В. В. Делба, В. И. Маландзия и др. Они вспомнили добрым словом Александра Федоровича Сидорова, подчеркнули преемственный характер данного научного форума.

Выводы по итогам проведенной в городах Сочи и Сухуме V международной научно-практической конференции могут быть сведены к следующим резюмирующим положениям:

1. Состоявшаяся Международная научно-практическая конференция, посвященная памяти крупного организатора экономической науки, профессора Александра Федоровича Сидорова и охватывающая весьма широкий спектр актуальных дискуссионных методологических и теоретических проблем, призвана способствовать преодолению «бессилия рыночных механизмов» и «узких» мест современного мейнстрима научных знаний в области эволюции теоретической экономики в прошлом и настоящем.

2. Проведение этого форума с привлечением представителей международного научного экономического сообщества из стран и регионов постсоветского пространства и публикация монографии по его материалам перед началом конференции позволяют своевременно информировать наибольшее число заинтересованных лиц об актуальных теоретико-методологических и историко-экономических нововведениях в российской и зарубежной экономической науке. 
3. Итоги конференции будут способствовать качественному обновлению предстоящих теоретико-методологических изысканий в области непреходящих ценностей феномена рыночного хозяйства, явятся импульсом для совершенствования практики хозяйственной жизни, возобновления и всемерного расширения традиций экономической науки на Юге России.

В своем заключительном слове Научный руководитель конференции д.э.н., профессор Яков Семенович Ядгаров поблагодарил Оргкомитет и всех участников состоявшегося форума за проведенную совместную работу. Подчеркнул, что материалы конференции в виде итоговой коллективной монографии ${ }^{2}$ были опубликованы перед ее началом и выразил уверенность в целесообразности продолжения сложившейся традиции, связанной с проведением ежегодного форума памяти профессора А. Ф. Сидорова.

\section{Информация об авторах}

Ядгаров Яков Семенович - доктор экономических наук, профессор, заведующий секцией истории экономической мысли, департамент экономической теории, Финансовый университет при Правительстве РФ, 101000, г. Москва, пер. Малый Златоустинский, д.7, стр.1, е-mail: yakovyadgarov@mail.ru.

Сидоров Виктор Александрович - доктор экономических наук, профессор, заведующий кафедрой теоретической экономики, Кубанский государственный университет, 350040, г. Краснодар, ул. Ставропольская, 149, e-mail: sidksu@mail.ru.

\section{an}

Yakov S. Yadgarov - D.Sc. in Economics, Professor, Head of the History of Economic Thought Division, Department of Economic Theory, Financial University under the Government

2 The phenomenon of the market economy: vectors and features evolution / ed. by V. A. Sidorov, Y. S. Yadgarov, V. V. Chaplya. L.: LSP, 2017. 620 p. 
of the Russian Federation, 7, building1,Small Zlatoustinsky lane, Moscow, 101000, Russian Federation, e-mail: yakovyadgarov@ mail.ru.

Viktor A. Sidorov - D.Sc. in Economics, Professor, Head of Theoretic Economics Department, Kuban State University, 149, Stavropolskaya str., Krasnodar, 350040, Russian Federation, e-mail: sidksu@mail.ru.

\section{Для цитирования}

Ядгаров Я. C. V Международная научно-практическая конференция «Феномен рыночного хозяйства: от истоков до наших дней» / Я. С. Ядгаров, В. А. Сидоров / / Историко-экономические исследования. - 2017. - Т. 18, № 2. C. 387-406. - DOI: 10.17150/2308-2588.2017.18(2).387-406.

\section{ए7:4}

Yadgarov Ya .S., Sidorov V. A. $5^{\text {th }}$ International Scientific Conference «Phenomenon of Market Economy: from the Origins until Now». Istoriko-ekonomicheskie issledovaniya = Journal of Economic History \& History of Economics, 2017, vol. 18, no. 2, pp. 387-406. DOI: 10.17150/2308-2588.2017.18(2).387-406. (In Russian). 